PHYSICAL REVIEW C 71, 019902(E) (2005)

\title{
Erratum: Exponential enhancement of nuclear reactions in a condensed matter environment [Phys. Rev. C 70, 047601 (2004)]
}

M. Yu. Kuchiev, B. L. Altshuler, and V. V. Flambaum

(Received 23 November 2004; published 1 February 2005)

DOI: 10.1103/PhysRevC.71.019902(E)

PACS number(s): 25.45.De, 25.60.Pj, 34.50-s, 99.10.Cd

The seventh line after Eq. (7) should read: “ $\ldots$ the reaction $t+p \rightarrow{ }^{4} \mathrm{He}+\gamma$." One additional reaction, $t+p \rightarrow{ }^{3} \mathrm{He}+n$, mentioned in that line has the $Q$ value of $-764 \mathrm{keV}$, which makes it impossible for it to occur at low collision energies. 